\title{
Personality traits and Risk taking attitudes among Firefighters of Rescue service
}

\author{
Yasir Riaz Gillani and Muhammad Atif \\ Department of Psychology, Government College University
}

Accepted: April 04, 2015

Doi:10.5296/ jpag.v5i1.7377 URL: http://dx.doi.org/10.5296/ jpag.v5i1.7377

\begin{abstract}
The Present Research was conducted to assess the Personality traits and Risk taking attitude among Firefighters of Rescue Service. The sample consisted of 63firefighters from rescue service of Lahore and Sialkot through purposive sampling technique. The NEO-FFI personality inventory (Costa \& McCrae, 2010) and Risk taking attitude survey scale (Stehman, 2012) was administered on all the participants. The correlation analysis, anova and independent sample t-test was applied to find out the statistical significance of the results. The results indicates that there are 31 firefighters having high score on risk taking attitude, 10 firefighters have normal risk taking attitude and 22 have low risk taking attitude. The lowest score on risk taking attitude is 21 and highest score on risk taking attitude is 55 . The firefighters have common personality type's extroverted, openness and conscientiousness. The result indicates that newly inducted or less experience firefighters has high risk taking attitude as compared to experienced firefighters. The firefighters of Lahore rescue service have high risk taking attitude as compared to Sialkot. The research is found that personality and risk taking attitude plays strong role in firefighters of rescue service.
\end{abstract}

Keywords: Personality traits, Risk taking attitudes, Firefighters, Rescue service 


\section{Introduction and Literature Review}

Rescue 1122 serves Punjab Province in Pakistan and it is an emergency service. The calling 1122 from any phone to access the rescue service. Management of services such as emergency of medical services, rescue and fire is provided under the Punjab Emergency Service Act 2006the rescue services established. Punjab Emergency Council and Districts Emergency Boards confirm to give the management and prevention of emergencies and different measure for public safety. In 2004 the Lahore Pilot Project launched and after its success, in all Districts of Punjab Rescue 1122 is operational and it provides technical assistance to other Provinces of Pakistan with a population of over 80 million. Recently, representing a model of integrated emergency services by Rescue 1122 in the world. It is offering rescue, emergency, disaster management, fire, animal rescue, water rescue, and community safety programs under one umbrella (Punjab Service Handbook, 2011).

When there is many attempts failure to increase, improve and modify the existing municipal fire brigades, there was a challenge that was accepted by the Rescue 1122 to establish first professionally trained and modern fire services in Pakistan. In order to achieve this challenge, six officers received fire instructor training from Strathclyde Fire and Rescue training center in the United Kingdom due to collaboration of Lahore with Glasgow city. The first modern and trained fire services are established on $5^{\text {th }}$ June, 2007 in Lahore which was applicable in all cities of Punjab. Rescue 1122 was able to save the precious human lives and losses worth approximately14.08 billion, as the result of professional fire fighting and timely response on modern lines while responding to 12,732 fire incidents (Naseer, 2009).

All personality theorists not agree on single definition of personality, there for, "personality is a pattern of unique characteristics and relatively permanent traits that give both individuality and consistency to a person's behavior" (Feist \& Feist, 2009). According to Diagnostic and Statistical Manual of American Psychological Association, Personality characteristics or traits are "enduring patterns of perceiving and thinking about oneself and the environment that are exhibited in a wide range of personal and social context." Theorists generally assume that a) characteristics differ among individuals, b) traits relatively stable over time and c) behavior is influenced from different characteristics or traits. They are continuously used for the help of people as whole.

Risk taking is some kind of behaviors that provide opportunity for some kind of outcome that can be perceived as positive and also at the same time the potential to be harmful and dangerous (Tull, 2014).There are some terms which used similarly like attitude, tolerance and appetite describe to individuals and an organizations attitude towards risk taking. There are some terms that may $\mathrm{b}$ used to describe risk attitude like risk averse, risk neutral and risk seeking. How much one is willing to accept risk is risk appetite and what is accepted which is acceptable or unacceptable is risk tolerance (Hansson, Ove \&Zalta, 2014).

There is a belief that firefighting is required deaths of firefighters held by some in fire services still today. The modern fire services leaders have attitude to trying their level best to save the occupation. The firefighter has high level of risk in this matter there is no dispute. There are changing in attitudes but there are many things to modify and complete. Retired 
Phoenix Fire Chief Alan Brunacini said prior to recent years, "Firefighters suffered the most unfair occupational discrimination in the United States, as it relates to health and safety" (Wolf,1998).

There are many reviews of firefighter's injury and fatality incidents and there are judgment errors on the acceptable risk level which come from firefighters and fire incident commanders. "Today's firefighters are perhaps the last of a dying breed" (Angione, 2001).The author cites the new morality among fire fighters. There are questioning to the firefighter about the danger of some of their retinue duties. Another writer states "civilian deaths and injuries have increased dramatically and ponders its impact on fire service. We have replaced 'how well we live' with 'how long we live'. It's unnatural and not a right way" (Manning, 1999). He worries about the greatness of fire services which will be destroy by the some regular paths.

Indeed the fire service culture honor to its heroes. When the members make efforts to save lives, the fire service department to give awards to heroism. Firehouse (2011), a magazine annually presents the community service and firehouse heroism award for the enthusiasts and firefighters. The public have perception that firefighter who is expected and willing to take risks is sometimes engrained into firefighter candidates even before they start their career. In this book, "Careers in Firefighting", the author quote a veteran fire officer, who states, "these men are the last American pioneers, for they face, with each day, with each fire, an uncertain future" (Lee \& Lee, 1993).

One fire chief writes, "Some in the fire service have the firefighter duty to die syndrome, which he euphemistically refers to as FTDS. It s condition where the firefighters believe they must take unacceptable level of risk to do their jobs properly, even to the point of death" (Crawford, 2007). He believes that fire service should analysis what energizes firefighters psychologically and how they find a solution in this type of behavior. For some risk takers if their needs are not fulfilled then the need of satisfaction and being as hero is increased as passage of time. In order to satisfy their needs there can be increasingly take dangerous actions or setting fires. There are many firefighters and fire experts who have believe that peer pressure can increase the risk taking behavior. According to another veteran chief, "some of the firefighters who have not had their turn on the tip at the big one yearn for the opportunity to prove them worthy of the recognition heaped upon the heroes of those past fires" (Gassaway, 2003). The author believes that there should not give any praise to those who make bad risk decision by fire service no matter the outcome.

The trend of the firefighter's death rate is troubling picture paint by NFPA. In the U.S there are regularly monitors and tracks firefighter fatalities and fire incidents by the NFPA. NFPA released a study in 2010 nothing structural fires and structural firefighter's deaths had decreased dramatically and on a same way, since 1977 . However, there is since the mid 2000s the firefighter's death rate has increased and the number of structural fires has remained relatively unchanged(NFPA, 2010).

Since 1998, in United States through the firefighter fatality investigation and prevention program National Institute for Occupational Health and Safety (NIOHS) has investigates fire 
fighters deaths and other serious or potentially serious injury cases. After every investigation there is a report which is issued to analysis the probability of causes for the fatality or injury and makes the recommendations on what to do to avoid the similar incidents (NIOHS, 2011).There are many studies on risk taking behavior of individuals have been conducted by psychologists. Marvin Zuckerman at the University of Delaware conducted the seminal research on this area where he has studied the topic since 1960. The work has been further refined by Zukerman (2007)and those using Zukerman's sensation seeking scales (SSS) test to learn why some individual needs sensation and thrills to feel complete. The definition provided by Zukerman (1994) is following, "Sensation seeking is a trait by the seeking of novel, varied, intense and complex sensations, experiences and willingness to take social, physical, financial and legal risks for the sake of such experience". In our everyday life risk is common part but sensation seekers have to accept more risk because they feel they will not suffer from negative impacts.

A Spanish psychologist looks at what motives firefighters in an article of Fire International. He believed that firefighters can be motivated by humanitarian urge and in other cases economic survival. According to the author if the firefighters acting according to those motivations then it can lead the person to assume risks that are out of keeping which his or her psyche and can cause psychological changes (Frago, 1999).

\subsection{Rationale of study}

Recently increasing risk taking attitude resulting fatalities, serious injuries and affects the psychological wellbeing of firefighters. It is also shahadat of firefighters of rescue service in gakhur plaza Rawalpindi .So it is the need of hour to explore the firefighters risk taking attitude and their personalities also factor affecting .

\subsection{Objectives}

1. Measure the risk taking attitude and personality traits of firefighters of rescue service.

2. To find out the relationship between personality traits and risk taking attitudes among firefighters of rescue service.

3. Effects of demographics on risk taking attitude of firefighters.

\subsection{Hypothesis}

1. There would be a significant correlation between personality traits and risk taking attitudes among firefighters of rescue service.

2. The risk taking attitudes of firefighters would be high having personality traits (extroversion and openness).

3. The risk taking attitude would be high among newly inducted or less experienced firefighters as compared to experienced firefighters.

4. The risk taking attitude would be high among unmarried firefighters as compared to married firefighters. 


\section{Research Method}

\subsection{Sample}

The sample consisted of 63 male firefighters of rescue service. Purposive sampling technique was used. The advantage of this sampling strategy was its lower cost compared to probability sampling and the easy accessibility regarding data/information to be collected.

\subsection{Inclusion Criteria}

Inclusion criteria set for the sample to be met:

- Current employees of Rescue service

- Employees work as firefighter

- Employees of Rescue service from Lahore and Sialkot

\subsection{Research design}

Present study comprised of Descriptive and Correlational study design. We will be Check the personality traits and risk taking attitude among firefighters of rescue service. This research design is used because we will see the relationship between risk taking attitude and personality traits among firefighters of rescue service and describe the phenomenon.

\subsection{Measures}

The instrument used for data collection is short version NEO Five - Factor Inventory (NEO-FFI) consists of 60 items and five subscales (neuroticism, extroversion, openness, agreeableness and conscientiousness) which consist of 12 items and severity labels from strongly disagree to strongly agree. Risk Taking Attitude scale consist of 18 items, 6 demographics and others derived from Zukerman's sensation seeking survey fifth version (SSS-V), Brief sensation seeking survey (BSSS-4) and Sensation seeking two-question model (SS2) and severity labels from take no risk to save property to always take risk to save property, never be taken to always be taken, never to very frequently, strongly disagree to strongly agree and some items true or false.

\subsection{Procedure}

The data was collected from firefighters of rescue service from two different cities Lahore and Sialkot. The inform consent was taken from all participants. The scales administered in group and individually as well. First the instructions were given to participants and told them the purpose of study and about confidentiality. First asked the participants to fill demographic sheet then Risk taking attitude scale and then NEO-FFI personality inventory. The time was given to participants that the Risk taking attitude scale items takes less than 3 minutes and personality inventory takes 20 to 40 minutes. Also told the participants that if they have any issue during fill the questionnaires then they can asked. All 63 participants filled out the demographics and two scales Risk taking attitude and NEO-FFI personality inventory. 


\section{Results}

Data analysis was conducted by using the SPSS 16.0 version for window. A sample of 63 subjects was taken for investigate personality traits and risk taking attitude among firefighters of rescue service. All Research Participants were selected from rescue service of Lahore and Sialkot. The results indicates that there are 31 firefighters having high score on risk taking attitude, 10 firefighters have normal risk taking attitude and 22 have low risk taking attitude. The lowest score on risk taking attitude is 21 and highest score on risk taking attitude is 55.The firefighters have common personality type's extroverted, openness and conscientiousness. The result indicates that newly inducted or less experience firefighters has high risk taking attitude as compared to experienced firefighters. The firefighters of Lahore rescue service have high risk taking attitude as compared to Sialkot. The research is found that personality and risk taking attitude plays strong role in firefighters of rescue service.

\section{Levels of Risk taking attitude}

\begin{tabular}{lll}
\hline No. of firefighters & Ranges & Category \\
\hline 31 & $37-55$ & High \\
10 & $34-36$ & Normal \\
22 & $21-33$ & Low \\
\hline
\end{tabular}

\section{Graphs}

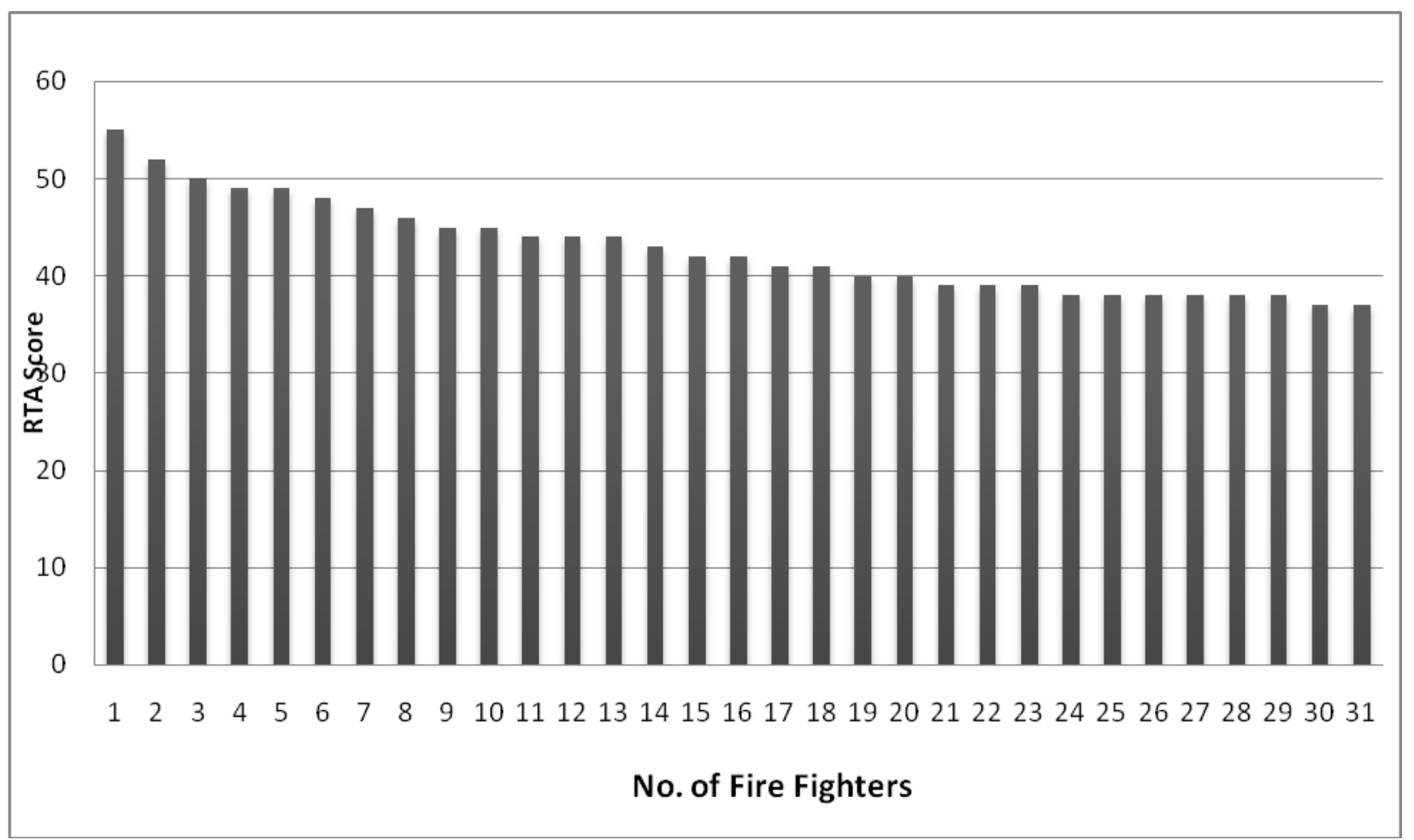



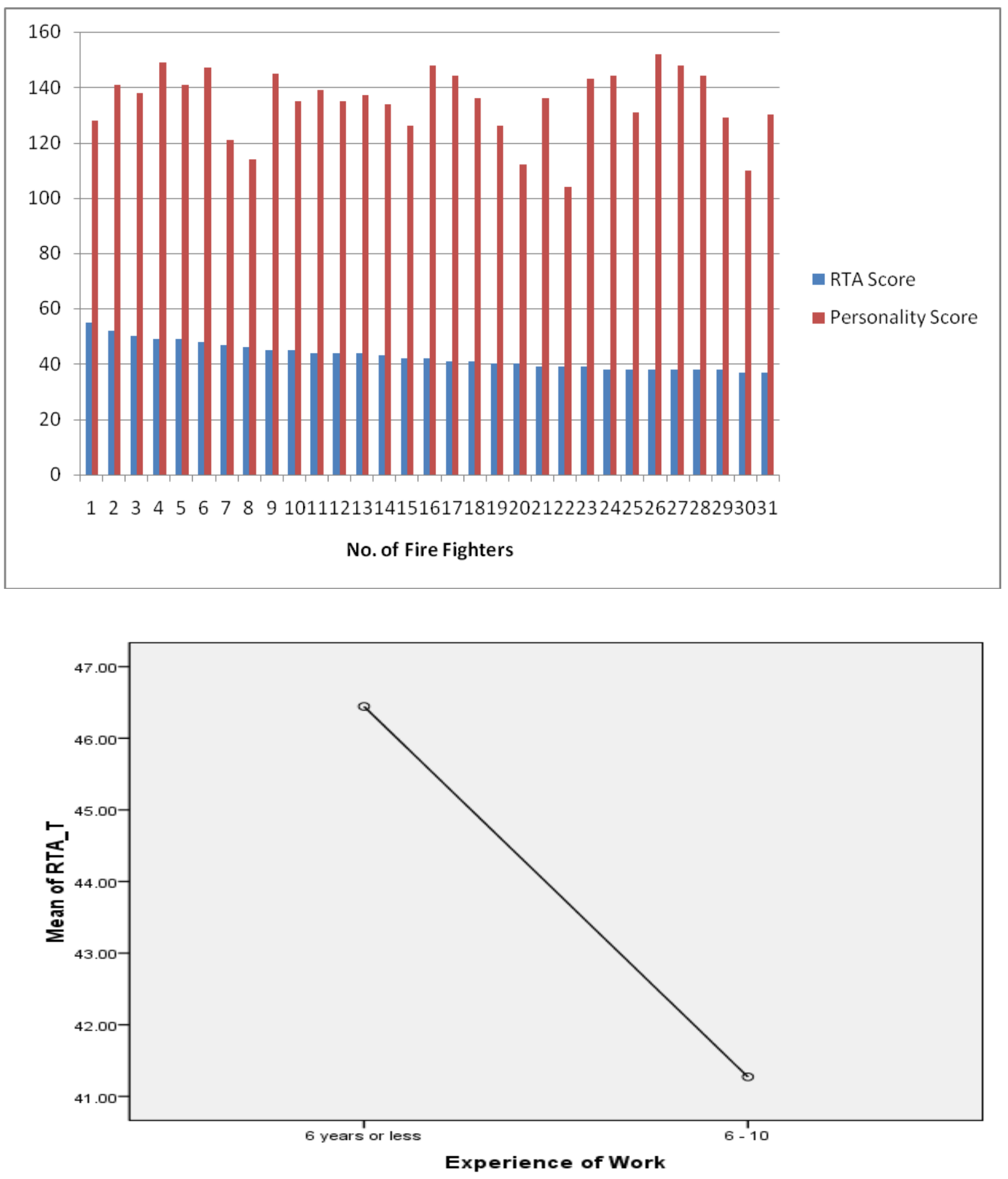
Table 1

Analysis Of Variance Anova for Risk Taking Attitude Among New Inducted or Less Experienced And Experienced Firefighters Of Rescue Service

\begin{tabular}{lllll}
\hline Sources & $d f$ & $M S$ & $F$ & $p$ \\
\hline Between groups & 1 & 170.833 & 9.302 & 0.05 \\
Within groups & 29 & 18.365 & & \\
Total & 30 & & & \\
\hline
\end{tabular}

Table 2

Descriptive for Risk taking attitude among new inducted or less experienced and experienced firefighters of Rescue service

\begin{tabular}{llllll}
\hline Groups & $N$ & $M$ & $S D$ & Min & Max \\
\hline 6 years or less & 9 & 46.44 & 5.15 & 39 & 55 \\
$6-10$ & 22 & 41.27 & 3.90 & 37 & 52 \\
Total & 31 & 42.77 & 4.84 & 37 & 55 \\
\hline
\end{tabular}

Table 3

Independent sample t-test for risk taking attitude among firefighters of lahore and sialkot rescue service.

\begin{tabular}{lllllcll}
\hline \multicolumn{7}{l}{ Lahore } & \multicolumn{2}{l}{ Sialkot } \\
\hline Analysis & $M$ & $S D$ & $M$ & $S D$ & $t$ & $p$ & $d f$ \\
\hline RTA & 38.54 & 7.67 & 33.50 & 5.51 & 2.72 & .04 & 61 \\
\hline
\end{tabular}

\section{Discussion}

The present study comprised of personality traits and risk taking attitude among firefighters of rescue service. The sample was consisting of 63 firefighters of rescue service. Risk taking attitude scale and NE0-FFI personality inventory scale used for collect the data. All Research Participants were selected from rescue service of Lahore and Sialkot. The results indicates that there are 31 firefighters having high score on risk taking attitude, 10 firefighters have 


\section{Al Macrothink}

normal risk taking attitude and 22 have low risk taking attitude. The lowest score on risk taking attitude is 21 and highest score on risk taking attitude is 55. The firefighters have common personality type's extroverted, openness and conscientiousness. The result indicates that newly inducted or less experience firefighters has high risk taking attitude as compared to experienced firefighters. The firefighters of Lahore rescue service have high risk taking attitude as compared to Sialkot. The research is found that personality and risk taking attitude plays strong role in firefighters of rescue service.

\section{Limitation}

There are some limitations in current research. The sample was limited due to shortage of time so the researcher selected the sample of 63 subjects. Result of this research cannot be generalized because of the sample size. The research was conducted in small area and limited time span.

\section{Suggestions}

There are some suggestions in current research. The sample should be large because if the sample will be large so respondents provide also large information. Then result can be generalized to the whole population. If gave a proper time for conducting research so the results will be more strong.

\section{References}

Feist \& Feist, J. (2009). What is Personality? http://psychology.about.com/od/overviewofpersonality/a/persondef.htm

Feist, Feist, J., \& Gregory, J. (2009). Theories of personality ( $7^{\text {th }}$ ed.). Boston: McGraw Hill Higher Education. ISBN 978-0073382708

Goldberg, L.R. (1990). An alternative "description of personality": The Big-Five factor structure. Journal of Personality and Social Psychology, 59, 1216-1229

Hansson, Ove, S., Edward, N. Z. (2014). Risk" The Stanford Encyclopedia of Philosophy. Retrieved 9 May 2014.

A Guide to the Project Management Body of Knowledge (4thed.). ANSI/PMI 99-001-2008 ISO/IEC 27005:2008

http://www.pakistantoday.com.pk/2013/03/18/city/islamabad/rescue-1122-gets-14-new-ambu lances/

http://lahoreworld.com/2013/2/16/rescue-1122-to-train-pakistan-armys-medical-corps

http://en.wikipedia.org/wiki/Rescue_1122

http://www.rescue.gov.pk/ManagementTeam.aspx

http://www.rescue.gov.pk/Introduction.aspx

http://en.wikipedia.org/wiki/Personality_psychology 